\title{
The Relationship between Regional Myocardial Perfusion at Rest and Arteriographic Lesions in Patients with Coronary Atherosclerosis
}

\author{
Paul J. Cannon, Donald H. Schmidt, Melvin B. Weiss, \\ Deborah L. Fowler, Robert R. Sciacca, Kent Ellis, and \\ William J. Casarella \\ From the Departments of Medicine and Radiology, College of Physicians and \\ Surgeons, Columbia University, New York 10032
}

A в S T R A C T Measurements of mean left ventricular (LV) and regional myocardial blood flow rates were made at rest in 161 patients with ${ }^{133} \mathrm{Xe}$ and a multiplecrystal scintillation camera. Myocardial perfusion rates were correlated with assessments of the degree of coronary artery disease made from the arteriograms obtained during the same studies. In patients with normal coronary arteries without heart failure, the presence of hypertension, aortic stenosis, or aortic insufficiency was not associated with changes in mean LV perfusion from the control value of $61 \pm 7 \mathrm{ml} / 100 \mathrm{~g} \cdot \mathrm{min}$. However, mean $\mathrm{LV}$ perfusion was significantly reduced in patients with normal coronary arteries who had cardiomyopathy and impaired ventricular performance. Mean LV perfusion was not significantly different from control values in patients with "mild" coronary artery disease $(<50 \%$ obstruction) or in patients with significant isolated disease (>50\% obstruction) of the left anterior descending (LAD) artery. Significant reductions in mean LV perfusion were found in patients with $>50 \%$ obstruction of two coronary arteries (LAD + right or LAD + circumflex) and in patients with triple-vessel disease.

The average perfusion rate for regions distal to LAD obstructions in patients with isolated LAD disease was not lower than the LAD perfusion in control patients, but was significantly reduced in patients with LAD + right coronary artery disease $(43 \pm 14 \mathrm{ml} / 100 \mathrm{~g} \cdot \mathrm{min})$. In the latter group average perfusion distal to the LAD lesion was significantly lower than the average regional perfusion rate for the remainder of the LV. However,

Dr. Cannon was the recipient of Career Development Award HL-15031 from the U. S. Public Health Service.

Received for publication 20 December 1974 and in revised form 4 August 1975. the mean blood flow rate for the remainder of the $\mathrm{LV}$ was also significantly lower than control values despite the lack of significant circumflex disease.

The data demonstrate that the presence of radiographically "mild" or significant isolated LAD coronary disease is not associated with reductions in mean LV perfusion at rest, but that mean LV perfusion is reduced in the presence of significant disease of two or three coronary arteries. None of the patients experienced angina during the resting studies and most had clinical evidence of ventricular failure. The observation of depressed LV perfusion in this group, as in the patients with cardiomyopathy, raises the possibility that a lowered resting blood supply may be adequate for a reduced level of performance of a diseased ventricle. The lack of selective reductions of regional perfusion at rest in the majority of the patients with LAD lesions suggests that regional myocardial blood flow must be measured during an intervention which increases myocardial oxygen consumption in order to assess the physiological significance of lesions which are observed at coronary arteriography.

\section{INTRODUCTION}

The relationship between resting myocardial blood flow and coronary artery disease has previously been the subject of several studies. Five groups of investigators found no significant differences in the myocardial capillary blood flow rates per gram of left ventricle $(\mathrm{LV})^{1}$ among groups of patients with normal coronary arterio-

${ }^{1}$ Abbreviations used in this paper: Circ., circumflex; LAD, left anterior descending; LAO, left anterior oblique; LM, left main; LV, left ventricle; LVEDP, left ventricular end-diastolic pressure. 
grams and others with significant coronary disease when they monitored single myocardial washout curves of nitrous oxide or radioactive inert gases (1-5). In contrast, Cannon et al. found average mean LV perfusion to be significantly lower in patients with two-vessel left coronary artery disease than in patients with normal left coronary arteriograms (6); they studied regional myocardial perfusion with ${ }^{133} \mathrm{Xe}$ and a multiple-crystal scintillation camera. A reduction in average LV blood flow per unit mass of tissue in a group of patients with advanced coronary disease has also been reported by Klocke et al., using the He washout technique with coronary sinus sampling (7). The differences in these reports may have been related to the different measurement techniques used to estimate myocardial blood flow.

The present study was designed to explore the relationships between coronary artery lesions visualized radiographically in patients with coronary artery disease and both the mean LV and the regional myocardial blood flow rates per unit mass of tissue which are present at rest. 161 patients with varying degrees of coronary atherosclerosis studied at The Columbia Presbyterian Medical Center are the subjects of this report. In each patient the regional and mean LV myocardial perfusion rates obtained with a radioisotopic method were correlated with independent standardized radiographic assessments of the severity and extent of the coronary vascular disease.

The technique used to measure blood flow in the present study employs a scintillation camera comprised of multiple collimated individual detectors to externally monitor ${ }^{133} \mathrm{Xe}$ washout curves from many areas of the myocardium (8). Regional myocardial blood flow rates in different areas of the heart are computed by the Kety formula $(8,9)$. Spatial separation of myocardial regions permits areas of myocardial underperfusion to be represented in the mean LV blood flow which is calculated by averaging the many regional perfusion rates measured in a given ventricle.

\section{METHODS}

Cardiac catheterization and coronary arteriography were performed only on patients for whom the studies were indicated clinically. Usual indications were a history of angina pectoris, atypical cardiac pain, congestive heart failure of uncertain etiology, and evaluation for cardiac valve surgery. Informed consent for the isotopic measurements of myocardial blood flow was obtained from each patient. The investigative protocols were approved by the Human Investigation and Joint Radioisotope Committees of The Columbia Presbyterian Medical Center. There were no complications related to the blood flow studies.

Coronary arteriography was performed by a modified Judkins technique (10). Images of contrast material injected into the coronary arteries were recorded on cine and/or serial cut films at a framing rate of 50 frames per second by using a 6-inch image intensifier and $35-\mathrm{mm}$ film. After visualization of each artery, the measurements of regional myocardial perfusion were performed. In most patients, roentgenographic assessments of LV volume and ejection fraction were also performed after contrast material was injected into the LV (11).

The radioisotopic measurements of regional myocardial perfusion were made by a method outlined briefly below. The method has been described in detail and illustrated previously $(6,8,12)$.

At the conclusion of diagnostic coronary arteriography, a left anterior oblique (LAO) cineangiogram was obtained with a series of radiopaque-radioactive markers positioned on the chest wall. 5-10 $\mathrm{min}$ was then allowed to elapse before measurements of myocardial blood flow were made. Without any change in the patient's position, the cine camera was replaced in the same plane and location by the head of the multiple-crystal scintillation camera. The multiplecrystal camera used for these studies (model 5600, Autofluoroscope, Baird Atomic, Inc., Bedford, Mass.) consists of a grid of 294 individual $\mathrm{NaI}(\mathrm{Tl})$ scintillation crystals arranged in 21 columns of 14 crystals. Each crystal is coupled by light pipes to two photomultiplier tubes arranged in an $(x, y)$ coordinate system. Scintillations occurring in each crystal are registered in a digital core memory and are recorded onto magnetic tape in locations which correspond to the positions of the separate crystals in the radiation detector. The positions of the precordial markers were recorded by the instrument and the markers were removed.

$20-25 \mathrm{mCi}$ of ${ }^{133} \mathrm{Xe}$ dissolved in $1-2 \mathrm{ml}$ of sterile pyrogenfree saline was injected rapidly into the main right or left coronary artery. ${ }^{133} \mathrm{Xe}$ passes by diffusion instantaneously into the myocardial tissue supplied by the coronary artery and is washed out from the tissue as a direct function of (nonradioactive) myocardial capillary blood flow (9). The $81-\mathrm{keV}$ gamma radiation emitted by the radioisotope during its arrival and washout from the myocardium was collimated by a 1.5-inch multichannel collimator and recorded externally by the multiple-crystal detector. Scintillations produced by incident photons were converted to an electrical signal, conditioned by anticoincidence circuitry and pulse height analysis (window settings, $70-250 \mathrm{keV}$ ), stored in the digital memory, and recorded onto the tape as counts per second for 4.5 to $7 \mathrm{~min}$.

The data was processed by a digital computer (model 360/91, IBM Corp., White Plains, N. Y.) located at the Columbia University Computer Center. Washout of ${ }^{209} \mathrm{Xe}$ from myocardial tissue was distinguished from the excretion of ${ }^{133} \mathrm{Xe}$ by the lungs with the aid of a computer printout of the peak counts per second recorded by each scintillation crystal and the number of seconds after the coronary injection of tracer that the peak counts per second occurred. Crystals overlying the myocardium supplied by the coronary artery recorded peak counts per second that were higher and appeared earlier than those recorded by crystals over the lungs. The computer fit a monoexponential equation by the method of least squares to the first 40 data points after the peak count recorded by each crystal and calculated the slope $(\kappa)$ of the initial portion of the myocardial ${ }^{133} \mathrm{Xe}$ washout curve, i.e., the clearance constant of ${ }^{133} \mathrm{Xe}$ washout from the myocardium viewed by the crystal. By using the Kety formula, the nutrient myocardial blood flow rates in the areas viewed by each of the multiple crystals were calculated, along with the standard deviation of each blood flow measurement: $F=\kappa \times \lambda / \rho$, where $F$ is the myocardial capillary blood flow in milliliters $/ 100 \mathrm{~g}$ per minute, $\lambda$ is the blood: myocardium partition coefficient for 
${ }^{133} \mathrm{Xe}$ obtained by Conn in the normal dog heart $(0.72)$ (13), and $\rho$ is the specific gravity of the tissue (1.05).

The patterns of local myocardial perfusion rates so obtained were then superimposed upon a tracing of the patient's LAO right or left coronary arteriogram (Fig. 1). Allignment and appropriate magnification of the two patterns were facilitated by the presence of the same radioactive-radiopaque markers on both the LAO coronary arteriogram and on the computer printout of local myocardial blood flow rates. A mean $\mathrm{LV}$ myocardial perfusion rate was calculated by averaging the local blood flows recorded by all of the crystals overlying the LV (Fig. 1a). The local perfusion rates of $\mathrm{LV}$ subregions supplied by the anterior descending (LAD) or the circumflex (Circ.) arteries were determined by averaging the perfusion rates of the appropriate crystals as defined from the tracing of the coro-

MEAN LV MYOCARDIAL FLOW $(61 \mathrm{ml} / 100 \mathrm{~g} \cdot \mathrm{min})$
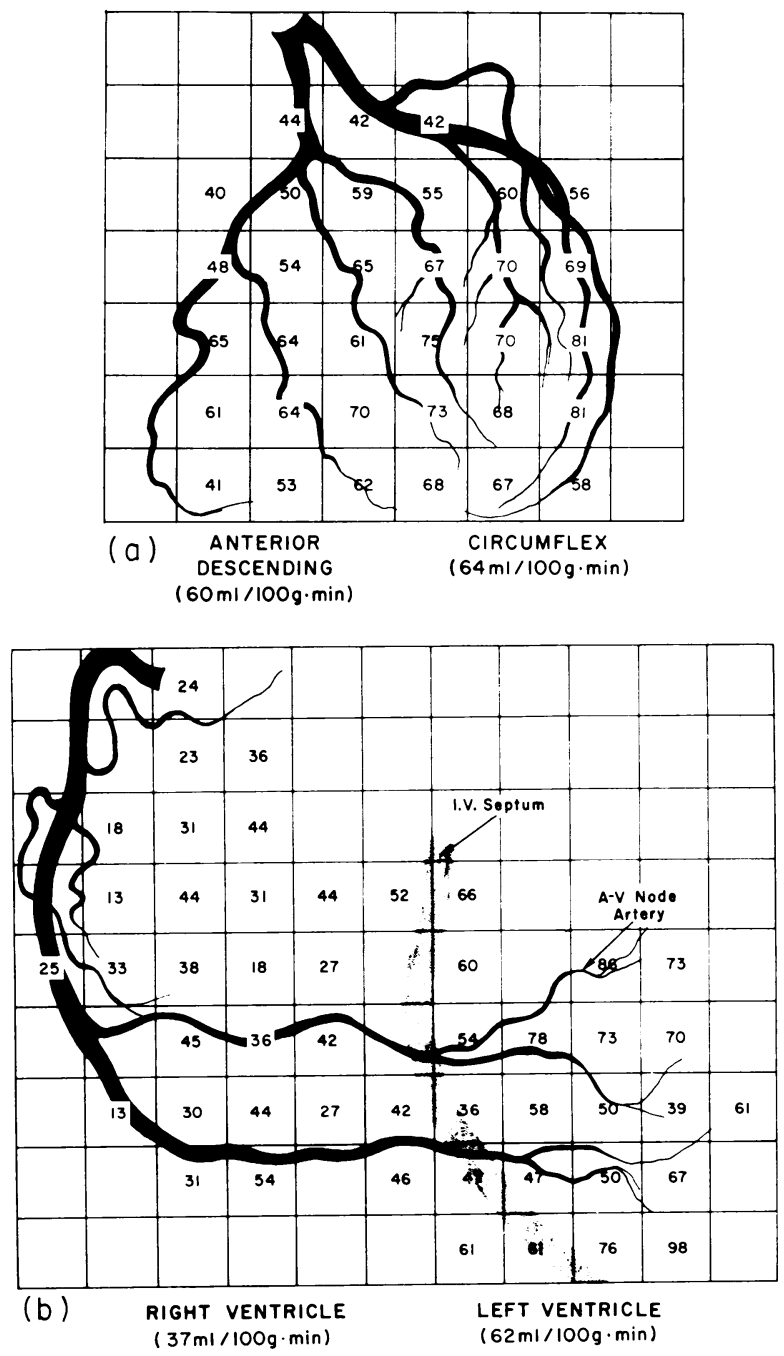

Figure 1 (a) The myocardial perfusion pattern from a study of a subject with a normal left coronary arteriogram. (b) The myocardial perfusion pattern from a study of a patient with an arteriographically normal dominant right coronary artery. nary arteriogram. Average perfusion rates in areas of myocardium proximal and distal to discrete coronary artery stenoses were also estimated. In right coronary artery studies, mean perfusion rates were also calculated for myocardial subregions (Fig. $1 b$ ). The proximal right coronary artery separated the right ventricular region from the right atrial area. The A-V node artery and the arteriographic "blush" in the interventricular septum separated the right ventricle from that portion of the inferior LV supplied by a dominant right coronary.

The coronary vascular lesions apparent on the cine and cut film coronary arteriograms were interpreted independently by at least one cardiologist and one radiologist (W. C.) and were coded by a modification of the scheme of Abrams (14). The right, left main (LM), LAD, and Circ. arteries were assessed individually (one-, two-, three-, fourvessel disease). Insignificant of "mild" coronary disease (class 0 ) was defined arbitrarily as the presence of obstructions of less than $50 \%$ of the lumen diameter. The grading " $1 \mathrm{~A}$ " indicated minor irregularity, whereas " $1 \mathrm{~B}$ " indicated obstructions of up to $50 \%$ which were not associated with prolonged transit of contrast material. Significant coronary disease (class 1-4) was defined as obstruction greater than $50 \%$ of any vessel or obstructions of $50 \%$ which were accompanied by delayed transit of contrast material. Significant disease was subdivided into grades: $2 \mathrm{~A}, 50-60 \%$ obstruction or $50 \%$ with slowing of contrast material; 2B, $60-80 \%$ obstruction ; 2C, $80-99 \%$ obstruction; $2 \mathrm{D}$, total occlusion. Total obstructions of major branches of a diameter $>50 \%$ of the parent vessel, such as the obtuse marginal, were classified as 2D. The obstructive lesions were numerically coded as follows: In the right, $\mathrm{LAD}$, and the Circ. branclies, lesions that had been graded were assigned the following scores: $1 \mathrm{~A}, 5 ; 1 \mathrm{~B}, 10 ; 2 \mathrm{~A}, 20$; $2 \mathrm{~B}, 30 ; 2 \mathrm{C}, 40 ; 2 \mathrm{D}, 50$. Lesions of the LM coronary were given a numerical score double that of the individual arteries, e.g., $1 \mathrm{~A}, 10 ; 2 \mathrm{~A}, 40$. The total score in each patient was calculated, and the average score in each group was determined. Similarly, the average distribution of severity of coronary artery lesions within each group of patients was calculated.

Radiographic criteria for describing vessels as collaterals were: (a) visualization of accessory blood vessels which either filled the distal segment of an occluded or stenotic coronary artery or supplied an area of myocardium distal to a lesion or $(b)$ visualization of a coronary artery after injection of contrast material into the contralateral artery. Collaterals were described as "inadequate" or "marginal" if the coronary artery supplied by the collateral vessels did not fill to a diameter of $1 \mathrm{~mm}$ or if the transit of contrast through the collateral vessels to the obstructed arterial segment was significantly delayed. "Adequate" collateral vessels were described as those that were clearly visualized, had a normal transit time for contrast material, and which filled the arterial segment beyond the coronary lesion to a diameter of at least $1 \mathrm{~mm}$.

\section{RESULTS}

Normal coronary arteries and "mild" coronary artery disease. The control subjects were 12 patients referred for study because of complaints of precordial pain, coronary risk factors, or a previous unexplained episode of congestive heart failure. None gave a history of chest discomfort that was typical of angina pectoris. At the time of cardiac catheterization, all had normal heart 
size, normal intracardiac pressures, normal left ventriculograms, and normal right and left coronary arteriograms (Table I). The mean myocardial blood flow rates for the LV in the control group averaged $61 \mathrm{ml} / 100 \mathrm{~g}$. min (Table II); individual values appear in Fig. 2. The average blood flow rate in the myocardial subregion supplied by the LAD was $60 \mathrm{ml} / 100 \mathrm{~g} \cdot \mathrm{min}$ and not significantly different from that of the Circ. subregion, $62 \mathrm{ml} / 100 \mathrm{~g} \cdot \mathrm{min}$. Individual LAD regional perfusion rates are graphed in Fig. 3. The peak count rates recorded by crystals overlying the LAD and Circ. subregions were also not significantly different from each other. The coefficient of variation of the multiple measurements of local LV myocardial perfusion made in each subject averaged $18 \%$. This variation includes both variation in local LV perfusion rates and measurement error. The variance of the local flow rates significantly exceeded the variance of the standard deviation of each individual perfusion measurement $(P<0.05)$ indicating mild heterogeneity of $\mathrm{LV}$ perfusion in these subjects with normal coronary arteriograms and normal cardiac hemodynamics.

10 patients had "mild" coronary disease and an average arteriographic score of 10 . The average mean LV blood flow rate in this group, $59 \pm 17 \mathrm{ml} / 100 \mathrm{~g} \cdot \mathrm{min}$, and the blood flow rates in the myocardial subregions sup-

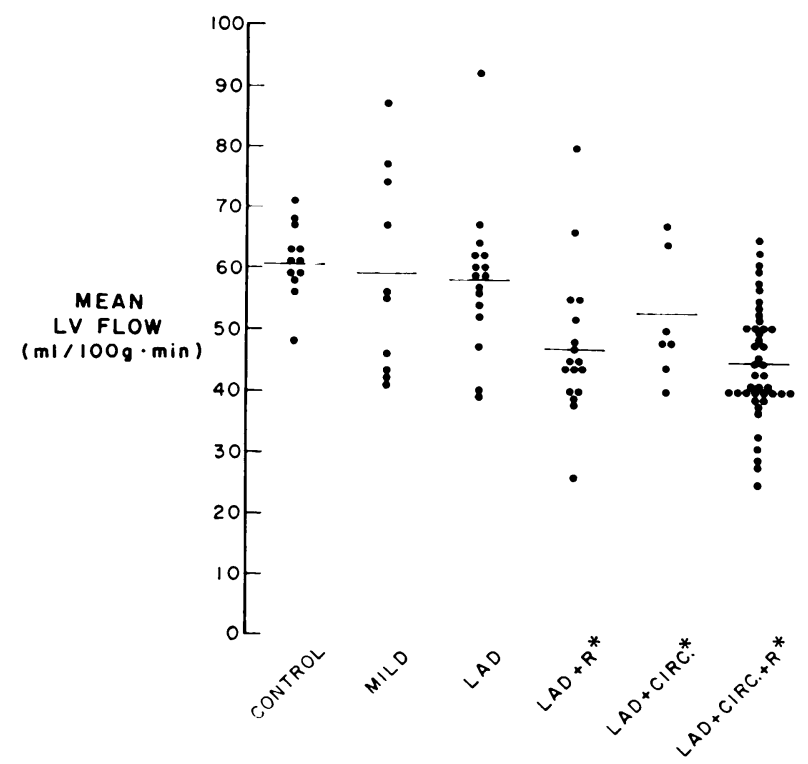

FIGURE 2 The mean LV myocardial blood flow rates/unit mass of tissue are plotted for patients grouped by the degree of atherosclerosis apparent on the coronary arteriograms. The average mean LV myocardial blood flow rate was significantly reduced below that of the control group in patients with radiographically significant lesions of the $\mathrm{LAD}+$ right $(\mathrm{R})$, the LAD + Circ., and LAD+ Circ. + right coronary arteries. * Significantly reduced below control.

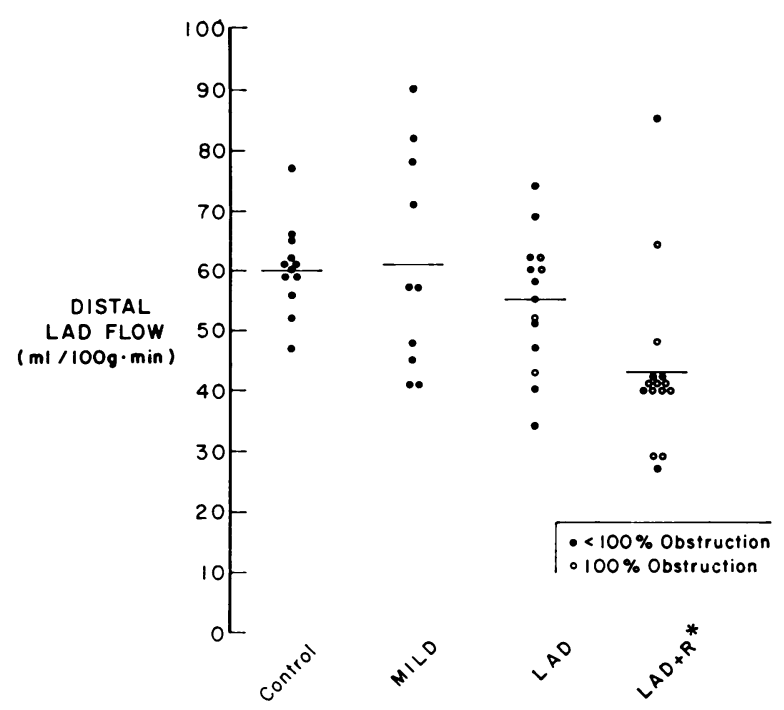

Figure 3 Blood flow rates in the myocardial subregions distal to LAD lesions in individual patients are plotted. The average distal LAD regional perfusion was reduced significantly below that of the controls in the groups with radiographically significant lesions of the LAD + right coronary arteries. * Significantly reduced below control.

plied by the LAD and Circ. arteries were not significantly lower than the values found in the control subjects (Tables I and II).

19 patients with essential hypertension, mild aortic stenosis, or aortic insufficiency had normal coronary arteriograms. The average mean LV myocardial blood flow rate in these patients was not significantly different from that of the control group (Fig. 4). In contrast, the average mean LV perfusion was significantly reduced below the controls in 15 patients with normal coronary arteriograms who had depressed ventricular performance due to cardiomyopathy. In another 19 patients with the four heart diseases, there were no significant reductions in average mean $L V$ perfusion rates from the respective control values when "mild" coronary artery lesions were visualized.

Significant one-vessel disease: isolated LAD lesions. ${ }^{2}$ The average total arteriographic score was 47 in 16 patients with isolated significant lesions of the LAD. The average mean LV myocardial blood flow rate in this group, $58 \mathrm{ml} / 100 \mathrm{~g} \cdot \mathrm{min}$, was not statistically different from the average mean LV perfusion rate found in the controls. Mean LV perfusion rates for the individual patients appear in the third column of Fig. 2.

\footnotetext{
${ }^{2}$ An insufficient number of studies of regional perfusion were performed on patients with LM coronary disease, isolated right coronary disease, isolated Circ. disease, or Circ. + right coronary disease to develop statistical comparisons with the control subjects.
} 
TABLE

Clinical, Hemodynamic, and

\begin{tabular}{|c|c|c|c|c|c|c|c|c|}
\hline \multirow[b]{3}{*}{ Group } & \multirow{3}{*}{$\begin{array}{c}\text { No. of } \\
\text { patients }\end{array}$} & \multirow{2}{*}{\multicolumn{2}{|c|}{ Sex }} & \multirow{2}{*}{\multicolumn{2}{|c|}{ Age }} & \multicolumn{3}{|c|}{ Number of patients with: } \\
\hline & & & & & & & & \multirow[b]{2}{*}{ MI } \\
\hline & & iI & $\mathrm{F}$ & Range & Mean & Angina & Atypical & \\
\hline Controls & 12 & 2 & 10 & 23-62 & 47 & 0 & 9 & 0 \\
\hline Mild disease & 10 & 2 & 8 & $36-62$ & 53 & 5 & 4 & 2 \\
\hline \multicolumn{9}{|l|}{ LAD } \\
\hline$<2 \mathrm{D}$ & 11 & 7 & 4 & $34-62$ & 52 & 6 & 2 & 3 \\
\hline $2 \mathrm{D}$ & 5 & 4 & 1 & $48-63$ & 55 & 5 & 0 & 3 \\
\hline Total & 16 & 11 & 5 & $34-63$ & 53 & 11 & 2 & 6 \\
\hline \multicolumn{9}{|l|}{ LAD + right } \\
\hline$<2 \mathrm{D}$ & 6 & 4 & 2 & $45-65$ & 55 & 6 & 0 & 3 \\
\hline $2 \mathrm{D}$ & 11 & 10 & 1 & $34-64$ & 50 & 10 & 0 & 7 \\
\hline Total & 17 & 14 & 3 & $34-65$ & 52 & 16 & 0 & 10 \\
\hline LAD + Circ. & 8 & 7 & 1 & $45-67$ & 5.5 & 7 & 1 & 5 \\
\hline LAD + Circ. + right & 45 & +2 & 3 & $32-68$ & 52 & 35 & 2 & 32 \\
\hline
\end{tabular}

$\mathrm{BP}$, blood pressure; $\mathrm{CHF}$, congestive heart failure; $\mathrm{HR}$, heart rate; $\mathrm{MI}$, myocardial infarction.

The average score for the LAD artery in these patients was 38 and the scores for each of the other three arteries were less than 5 . With arteriographic landmarks, the average resting perfusion rates and peak count rates observed in the myocardial region distal to the coronary obstruction on the LAO perfusion pattern were compared to the respective average values found in the rest of the same ventricles in 14 patients. The average mean regional myocardial blood flow rate distal to the LAD lesion, $55 \pm 11 \mathrm{ml} / 100 \mathrm{~g} \cdot \mathrm{min}$, was not significantly different from the average mean perfusion rate for the remainder of the ventricle, $57 \pm 8 \mathrm{ml} / 100 \mathrm{~g}$. $\min$ (Table II) or from the average mean LAD regional perfusion rate for the control group, $60 \pm 7 \mathrm{ml} / 100 \mathrm{~g}$. min (Fig. 3). Similarly the average peak count rate recorded by crystals distal to the lesions were not different from the corresponding values for the remainder of the LV. In three patients the myocardial perfusion rate distal to the LAD lesion was $<45 \mathrm{ml} / 100 \mathrm{~g} \cdot \min$ (Fig. 3). The same three patients had similarly depressed blood flow in the remainder of the I.V and had abnormal ventriculograms.

Significant two-vessel disease: $L A D+$ right lesions. The total arteriographic score averaged 90 in the 17 pa- tients with significant disease of the LAD and right coronary arteries. The average scores in the two vessels were 41 and 39 , respectively. The mean LV myocardial blood flow rates in this group averaged $47 \pm 12 \mathrm{ml} / 100$ $\mathrm{g} \cdot \mathrm{min}$. This was significantly lower than the average mean LV blood flow observed in the control subjects $(P<0.01)$ and in those with "mild" coronary disease $(P<0.05)$. Individual mean $\mathrm{LV}$ perfusion rates in the LAD + right group are depicted in the fourth column of Fig. 2.

The average myocardial blood flow rate in the subregion distal to the LAD lesion (Fig. 3) in 15 of this group was $43 \pm 14 \mathrm{ml} / 100 \mathrm{~g} \cdot \mathrm{min}$, a value significantly lower (paired analysis) than the average myocardial blood flow rate of $49 \pm 13 \mathrm{ml} / 100 \mathrm{~g} \cdot \mathrm{min}$ measured elsewhere in the same ventricles. However, the average blood flow rate for the remainder of the $L V$ in this group was also significantly lower than the average regional blood flow rates found in the LAD or the Circ. areas of the control group. The average peak count rate recorded by crystals overlying the region distal to the LAD lesion was significantly reduced below the average peak count rate recorded in the remainder of the ventricle (356 vs. $486 \mathrm{cps}, P<0.05$ ). In 11 patients, sig- 
Ventriculographic Data

\begin{tabular}{|c|c|c|c|c|c|c|c|c|c|}
\hline \multicolumn{2}{|c|}{ Number of patients with: } & \multicolumn{2}{|c|}{$\mathrm{BP}$} & \multirow[b]{2}{*}{$\mathrm{HR}$} & \multicolumn{2}{|c|}{ LV pressure } & \multirow{2}{*}{$\begin{array}{c}\text { No. of } \\
\text { natients } \\
\text { with } \\
\text { LVEDP } \\
>12 \mathrm{~mm} \mathrm{Hg}\end{array}$} & \multicolumn{2}{|c|}{ Ventriculogram } \\
\hline $\mathrm{CHF}$ & Cardiomegaly & Sys. & Dias. & & Sys. & Dias. & & motion & Aneurysm $s$ \\
\hline & & \multicolumn{2}{|c|}{$m m \mathrm{Hg}$} & & & & & & \\
\hline \multirow[t]{2}{*}{1} & 0 & 133 & 79 & 85 & 129 & 8 & 0 & 0 & 0 \\
\hline & & \pm 23 & \pm 12 & \pm 9 & \pm 21 & \pm 3 & & & \\
\hline \multirow[t]{2}{*}{1} & 0 & 132 & 73 & 74 & 127 & 12 & 3 & 0 & 0 \\
\hline & & \pm 16 & \pm 4 & \pm 8 & \pm 22 & \pm 6 & & & \\
\hline \multirow[t]{2}{*}{2} & 1 & 138 & 78 & 81 & 135 & 9 & 1 & 4 & 0 \\
\hline & & \pm 21 & \pm 8 & \pm 11 & \pm 20 & \pm 3 & & & \\
\hline \multirow[t]{2}{*}{2} & 2 & 130 & 76 & 80 & 144 & 17 & 5 & 3 & 1 \\
\hline & & \pm 7 & \pm 9 & \pm 19 & \pm 22 & \pm 2 & & & \\
\hline \multirow[t]{2}{*}{4} & 3 & 136 & 77 & 81 & 138 & 11 & 6 & 7 & 1 \\
\hline & & \pm 18 & \pm 8 & \pm 13 & \pm 21 & \pm 5 & & & \\
\hline \multirow[t]{2}{*}{2} & 3 & 131 & 69 & 78 & 125 & 11 & 1 & 3 & 1 \\
\hline & & \pm 24 & \pm 10 & \pm 8 & \pm 28 & \pm 8 & & & \\
\hline \multirow[t]{2}{*}{5} & 6 & 113 & 70 & 79 & 114 & 17 & 6 & 4 & 3 \\
\hline & & \pm 16 & \pm 12 & \pm 11 & \pm 15 & \pm 8 & & & \\
\hline \multirow[t]{2}{*}{7} & 9 & 120 & 68 & 78 & 118 & 14 & 7 & 7 & 4 \\
\hline & & \pm 21 & \pm 11 & \pm 10 & \pm 21 & \pm 9 & & & \\
\hline \multirow[t]{2}{*}{2} & 2 & 126 & 71 & 84 & 129 & 16 & 4 & 4 & 1 \\
\hline & & \pm 20 & \pm 7 & \pm 13 & \pm 26 & \pm 8 & & & \\
\hline \multirow[t]{2}{*}{15} & 18 & 124 & 77 & 82 & 121 & 18 & 25 & 31 & 6 \\
\hline & & \pm 23 & \pm 14 & \pm 12 & \pm 20 & \pm 9 & & & \\
\hline
\end{tabular}

nificant depression of regional distal LAD flow was accompanied by depression of the flow in the remainder of the LV. Seven of this latter group had an increased left ventricular end-diastolic pressure (LVEDP), and seven had abnormal ventriculograms (Table I).

Significant two-vessel disease: $L A D+$ Circ. lesions. In the eight patients with significant disease of the LAD and Circ. arteries the average total arteriographic score was 82 . The average scores for the LAD and Circ. were 38 and 38 , respectively.

The average mean LV myocardial blood flow rate of $53 \pm 10 \mathrm{ml} / 100 \mathrm{~g} \cdot \mathrm{min}$ and the perfusion rates in the LAD $(51 \pm 11 \mathrm{ml} / 100 \mathrm{~g} \cdot \mathrm{min})$ and the Circ. $(51 \pm 11 \mathrm{ml} /$ $100 \mathrm{~g} \cdot \mathrm{min})$ subregions were reduced significantly below the corresponding values found in the control group. The mean LV perfusion rates in each patients are depicted in the fifth column of Fig. 2.

Significant triple-vessel disease: $L A D+$ Circ. + right lesions. 45 patients with significant triple-vessel disease had an average arteriographic score of 130 . The average scores for the individual vessels were: right, 42 ; LM, 3; LAD, 43; Circ., 41.15 patients manifested congestive failure, 18 had cardiomegaly, 25 had an elevated LVEDP, and 31 had abnormal ventriculograms (Table I).
Average mean $\mathrm{LV}$ myocardial blood flow rates were diffusely reduced in the patients with significant triplevessel coronary disease. The average mean LV perfusion rate of $45 \pm 9 \mathrm{ml} / 100 \mathrm{~g} \cdot \mathrm{min}$ and the blood flow rates of the LAD and Circ. subregions were significantly reduced below the respective values found in the control group $(P<0.01)$ and in those with isolated LAD disease $(P<0.01)$ (Table II, Fig. 2). Although the average mean LV myocardial blood flow rate was also lower than that observed in the patients with two-vessel disease $(\mathrm{LAD}+$ right and LAD + Circ.), the differences did not attain statistical significance. Heterogeneity of LV myocardial perfusion was increased in the patients with triple-vessel disease. The average coefficient of variation of the multiple local $\mathrm{LV}$ perfusion rates measured in each patient was $23 \%$, a value significantly higher than the $18 \%$ observed in the control patients. An example of a perfusion pattern of a patient with triple-vessel disease is depicted in Fig. 5.

Correlations of regional and mean $L V$ perfusion with arteriographic scores. The relationship between perfusion values and arteriographic scores was assessed by a nonparametric statistical technique (Spearman's coefficient of rank correlation). The regional perfusion rates 
TABLE

Coronary Arteriographic Scores and Measurements on

\begin{tabular}{|c|c|c|c|c|c|c|c|c|}
\hline \multirow[b]{2}{*}{ Group } & \multicolumn{5}{|c|}{ Arteriographic scores } & \multicolumn{3}{|c|}{$\mathrm{LV}$ perfusion } \\
\hline & Total & Right & $\mathrm{LM}$ & LAD & Circ. & $\mathrm{LV}$ & $\mathrm{LAD}$ & Circ. \\
\hline & & & & & & \multicolumn{3}{|c|}{$\mathrm{ml} / 100 \mathrm{~g} \cdot \mathrm{min}$} \\
\hline \multirow[t]{2}{*}{ Controls } & 0.0 & 0.0 & 0.0 & 0.0 & 0.0 & 61 & 61 & 62 \\
\hline & & & & & & \pm 6 & \pm 8 & \pm 7 \\
\hline \multirow[t]{2}{*}{ Mild disease } & 10.0 & 3.5 & 0.0 & 5.0 & 1.5 & 59 & 61 & 54 \\
\hline & & & & & & \pm 17 & \pm 18 & \pm 1.3 \\
\hline \multicolumn{9}{|l|}{ LAD } \\
\hline \multirow[t]{2}{*}{$<2 \mathrm{D}$} & 41 & 4 & 1 & 33 & 3 & 55 & 55 & 53 \\
\hline & & & & & & \pm 9 & \pm 12 & \pm 9 \\
\hline \multirow[t]{2}{*}{$2 \mathrm{D}$} & 60 & 5 & 0 & 50 & 5 & 66 & 61 & 66 \\
\hline & & & & & & \pm 15 & \pm 21 & \pm 11 \\
\hline \multirow[t]{2}{*}{ Total } & 47 & 4 & 1 & 38 & 4 & 58 & 59 & 55 \\
\hline & & & & & & \pm 11 & \pm 15 & \pm 13 \\
\hline \multicolumn{9}{|l|}{ LAD + right } \\
\hline \multirow[t]{2}{*}{$<2 \mathrm{D}$} & 66 & 37 & 0 & 25 & 4 & 47 & 48 & 46 \\
\hline & & & & & & \pm 18 & \pm 20 & \pm 16 \\
\hline \multirow[t]{2}{*}{$2 \mathrm{I})$} & 10.3 & 41 & 6 & 50 & 5 & 47 & 43 & 50 \\
\hline & & & & & & \pm 9 & \pm 11 & \pm 8 \\
\hline \multirow[t]{2}{*}{ Total } & 90 & 39 & 4 & 41 & 5 & 47 & 46 & 49 \\
\hline & & & & & & \pm 12 & \pm 15 & \pm 12 \\
\hline \multirow[t]{2}{*}{ LAD + Circ. } & 82 & 6 & 1 & 38 & 38 & 53 & 51 & 51 \\
\hline & & & & & & \pm 10 & \pm 11 & \pm 11 \\
\hline \multirow[t]{2}{*}{ LAD + Circ. + right } & 130 & 42 & 5 & 43 & 41 & 45 & 44 & 44 \\
\hline & & & & & & \pm 9 & \pm 10 & \pm 9 \\
\hline
\end{tabular}

distal to LAD lesions were significantly but poorly correlated with the arteriographic scores for the artery $(r=-0.38, P<0.01)$. Likewise, the total arteriographic score for the 108 patients without cardiomyopathy, hypertension, or valvular disease was significantly correlated with mean LV perfusion $(r=-0.45, P<$ 0.01) (Fig. 6).

\section{DISCUSSION}

Study design. Although arteriography permits visualization of coronary artery lesions, it provides no information concerning the effect of these lesions upon blood flow or information concerning the relationship between coronary perfusion and the metabolic demands of myocardial tissue. The purpose of the present study was to measure mean $\mathrm{LV}$ and regional myocardial blood flow rates in patients with coronary heart disease at rest and to compare these measurements with independent standard radiographic assessments of the coronary arterial disease. The coronary lesions in each patient were carefully evaluated from the arteriograms by radiologists using a widely accepted format (14) and having no knowledge of the myocardial perfusion data. For purposes of presentation, the patients were grouped by the significance and extent of disease in different ves- sels. Other investigators have measured the average LV myocardial blood flow per unit mass of tissue in patients and related this to coronary arteriographic lesions $(1-5,7)$. However, the distribution of lesions within the heart was not assessed in those reports, and measurements of blood flow in discrete regions of the myocardium were not performed.

Regional myocardial capillary blood flow in the $\mathrm{LV}$ in the present study was measured with ${ }^{133} \mathrm{Xe}$ and a multiple-crystal scintillation camera. This technique provides quantitative estimates of capillary perfusion in multiple regions of the heart after the radioisotope is injected into a coronary artery $(6,8,12)$. Computer analysis of the multiple local ${ }^{133} \mathrm{Xe}$ washout curves provides both accurate estimates of tracer clearance from heart muscle and statistical assessments of the accuracy of the measurements. It must be reemphasized, however, that the primary data obtained in these studies were the rate constants of ${ }^{133} \mathrm{Xe}$ washout from the individual areas of the heart viewed by the multiple detectors; these were calculated by monoexponential analysis of the initial portions of each tracer curve. The expression of the primary data in terms of blood flow (Table II) must be interpreted with caution to the extent that it involves the use of the Kety formula (9) with two constants, 
Mean LV and Regional Myocardial Blood Flow

\begin{tabular}{|c|c|c|c|c|c|c|}
\hline \multirow{2}{*}{$\begin{array}{l}\text { Coefficient } \\
\text { of } \\
\text { variation }\end{array}$} & \multicolumn{2}{|c|}{ Regional perfusion } & \multicolumn{2}{|c|}{ Peak counts } & \multirow{2}{*}{$\begin{array}{l}\text { Ratio of flows, } \\
\frac{\text { Distal }}{\text { Proximal }}\end{array}$} & \multirow{2}{*}{$\begin{array}{l}\text { Ratio of pea } \\
\text { counts. } \\
\text { Distal } \\
\text { Proximal }\end{array}$} \\
\hline & Distal & Proximal & Distal & Proximal & & \\
\hline$\%$ & \multicolumn{2}{|c|}{$\mathrm{ml} / 100 \mathrm{~g} \cdot \mathrm{min}$} & \multicolumn{2}{|c|}{$c p s$} & & \\
\hline \multirow[t]{2}{*}{18} & 60 & 62 & 462 & 446 & 1.02 & 1.03 \\
\hline & \pm 7 & \pm 7 & \pm 178 & \pm 162 & \pm 0.21 & \pm 0.11 \\
\hline \multirow[t]{2}{*}{20} & 61 & 55 & 553 & 530 & 1.10 & 1.09 \\
\hline & \pm 18 & \pm 13 & \pm 205 & \pm 234 & \pm 0.09 & \pm 0.24 \\
\hline \multirow[t]{2}{*}{20} & 55 & 55 & 471 & 567 & 1.00 & 0.86 \\
\hline & \pm 12 & \pm 8 & \pm 159 & \pm 196 & \pm 0.16 & \pm 0.27 \\
\hline \multirow[t]{2}{*}{18} & 54 & 62 & 217 & 452 & 0.88 & 0.50 \\
\hline & \pm 9 & \pm 4 & \pm 76 & \pm 164 & \pm 0.14 & \pm 0.13 \\
\hline \multirow[t]{2}{*}{19} & 55 & 57 & 399 & 534 & 0.97 & 0.76 \\
\hline & \pm 11 & \pm 8 & \pm 182 & \pm 189 & \pm 0.16 & \pm 0.29 \\
\hline \multirow[t]{2}{*}{23} & 47 & 47 & 432 & 453 & 0.99 & 0.94 \\
\hline & \pm 22 & \pm 20 & \pm 131 & \pm 78 & \pm 0.13 & \pm 0.15 \\
\hline \multirow[t]{2}{*}{23} & 41 & 49 & 317 & 503 & 0.83 & 0.65 \\
\hline & \pm 10 & \pm 8 & \pm 98 & \pm 150 & \pm 0.11 & \pm 0.16 \\
\hline \multirow[t]{2}{*}{23} & 43 & 49 & 356 & 486 & 0.89 & 0.75 \\
\hline & \pm 14 & \pm 13 & \pm 120 & \pm 129 & \pm 0.14 & \pm 0.21 \\
\hline \multicolumn{7}{|l|}{18} \\
\hline 23 & & & & & & \\
\hline
\end{tabular}

$\lambda$ and $\rho$, one of which $(\lambda)$ was obtained from studies of normal dog myocardium (13). Nevertheless, the primary observations in a patient or in a group of patients retain a validity which is independent of the assumptions involved in expressing the tracer clearance data in terms of blood flow per unit mass of tissue. Each regional myocardial ${ }^{133} \mathrm{Xe}$ clearance constant is a quantitative expression of the ability of the myocardial circulation to clear a diffusible indicator from the tissue and, by inference, to supply the tissue with diffusible nutrients.

Normal coronary arteries and mild coronary disease. The control subjects had normal coronary arteriograms, did not have angina, and had no hemodynamic or ventriculographic evidence of ventricular malfunction at the time of study. Abnormalities on the ECG of four and a past history of congestive failure in one suggest that some of the group had occult heart disease, however. The average mean LV myocardial blood flow rate of 61 $\mathrm{ml} / 100 \mathrm{~g} \cdot \mathrm{min}$ in this group is similar to the value of $64 \mathrm{ml} / 100 \mathrm{~g} \cdot \min$ obtained previously in a series of patients with heart disease and normal coronary arteriograms who were studied at Roosevelt Hospital (6). It is similar also to control values obtained by others who measured single myocardial washout curves of ${ }^{133} \mathrm{Xe}$ or $\mathrm{He}(2,7)$, but is lower than those obtained by groups using the nitrous oxide technique $(1,15,16)$, which has yielded a wide range of values in normal subjects (17). In the control subjects, the regional myocardial blood flow rates in the areas of LV supplied by the LAD and Circ. arteries did not differ significantly from each other (61 and $62 \mathrm{ml} / 100 \mathrm{~g} \cdot \mathrm{min}$ ). The $18 \%$ variability in the local LV perfusion rates in the control subjects significantly exceeded the variability of the standard deviations of the individual flow measurements (error term). This result confirms a previous finding (6) and is indicative of a mild $(<18 \%)$ heterogeneity of local myocardial perfusion rates in the LV of patients with normal coronary arteriograms. LV myocardial blood flow heterogeneity has also been reported in patients and in dogs with normal coronary arteries by investigators who used other techniques to estimate regional myocardial perfusion (18-20).

The total and regional myocardial blood flow rates were not significantly reduced below those of the control group in 29 patients with $<50 \%$ obstructions on the coronary arteriograms. These data are consistent with data of Smith et al. (21), who found in studies made in the operating room that coronary arterial blood pressures and myocardial blood flow rates distal to $<80 \%$ coronary artery lesions were normal, whereas pressures 


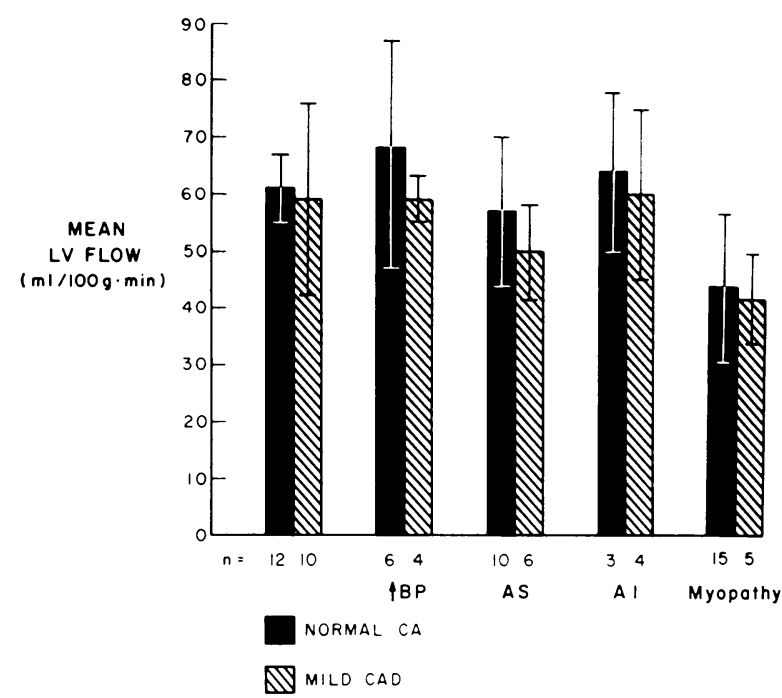

Figure 4 Mean LV myocardial blood flow rates in 75 patients without radiographically significant coronary artery disease (CAD) are plotted. Mean LV perfusion in patients with normal coronary arteriograms (CA) and essential hypertension $(\uparrow B P)$, mild aortic stenosis (AS), or aortic insufficiency (AI) was not different from the control group. Mean LV perfusion was significantly reduced in patients with cardiomyopathy. In all five groups, the presence of "mild" coronary atherosclerosis by arteriography was not associated with significant reductions of mean I.V perfusion from respective controls.

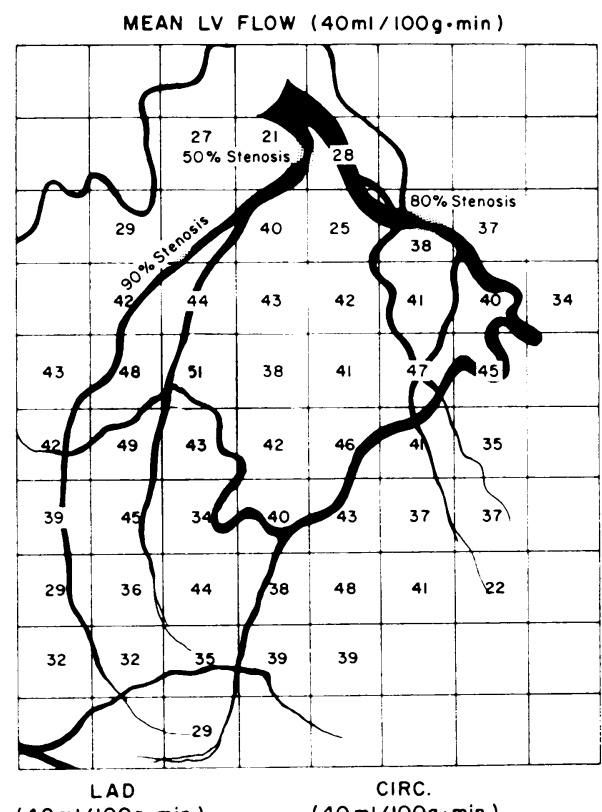

$(42 \mathrm{ml} / 100 \mathrm{~g} \cdot \mathrm{min})$

$(40 \mathrm{ml} / 100 \mathrm{~g} \cdot \mathrm{min})$

Figure 5 The myocardial perfusion pattern from a study of a patient with radiographically significant disease of three coronary vessels. The patient had an increased I.VEDP and diffusely hypokinetic ventricular contractions.

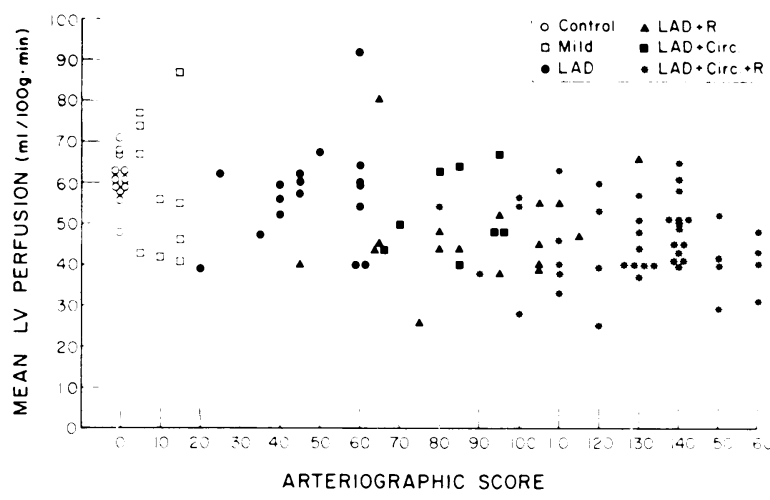

Figure 6 Correlation between mean LV perfusion and the total arteriographic atherosclerotic score in 108 patients without cardiomyopathy, hypertension, or aortic valvular disease $(r=-0.45, P<0.001)$.

and flows distal to lesions $>80 \%$ were reduced. Gould et al. (22), using flowmeters in dogs during progressive coronary constriction, reported that resting coronary flow was not reduced until the lumen diameter was narrowed $85-90 \%$ but that the hyperemic response to injection of contrast material fell progressively with constrictions $>35 \%$.

In the studies of patients with normal coronary arteriograms who had essential hypertension, mild aortic stenosis, or aortic insufficiency and myocardial hypertrophy without evidence of ventricular failure, the average mean LV perfusion rates were not different from that of the controls (Fig. 4). In contrast, there was a significant reduction in the average mean $\mathrm{LV}$ perfusion rate per unit mass of tissue in patients with normal arteriograms who had depressed ventricular function secondary to cardiomyopathy. In unpublished studies, LV myocardial blood flow rates in patients with cardiomyopathy increased uniformly in response to atrial pacing to the levels found in the control subjects at rest. This observation plus other studies in animals (23) and patients (24) suggest that there is a relationship between the resting level of myocardial perfusion and three of the major determinants of myocardial oxygen consumption, heart rate, peak wall stress, and contractility. These demonstrations that there are differences in resting $\mathrm{LV}$ myocardial perfusion rates in animals or patients with normal coronary arteries imply that the effect of significant coronary lesions upon regional myocardial blood flow must be interpreted against the background relationship between myocardial blood flow and ventricular performance which exists in a given patient at the time of study.

Radiographically significant coronary disease: mean $L V$ perfusion. The average mean LV perfusion per unit mass of tissue was not significantly different from con- 
trols in the patients with radiographically significant isolated LAD disease. This may have several explanations: (a) The average degree of LAD stenosis in the group (LAD score, 38 ) corresponds to a lesion of 60 $80 \%$ which might not have been sufficient to reduce resting flow $(21,22)$. (b) Even though regional perfusion was reduced distal to the LAD lesions in a few individuals (Fig. 3 ) the much larger LV regions of normal blood flow brought the average mean LV perfusion rate within the range of normal.

The average mean LV perfusion was significantly reduced, however, in the 70 patients with radiographically significant two- and three-vessel coronary disease (LAD + right, LAD + Circ., LAD + Circ. + right). This observation is in conflict with previous reports of normal flow/unit mass in coronary patients by workers who measured the myocardial washout of inert gases with coronary sinus blood sampling or with a single precordial scintillation detector $(2,3,5)$. However, it confirms in a large population our previous finding that mean LV perfusion/unit mass of tissue was reduced in patients with significant disease of two left coronary vessels (6). Recently Klocke and co-workers also reported that mean $\mathrm{LV}$ perfusion was reduced in a series of patients with arteriographically "advanced" coronary disease who were studied with the He washout technique and coronary sinus sampling (7). Hodges et al., using the same $\mathrm{He}$ technique, found reduced LV perfusion/mass of tissue in a series of patient with acute myocardial infarction (25). The differences in the reports probably relate to methodological differences. Studies in dogs with coronary occlusions indicate that the $\mathrm{N}_{2} \mathrm{O}$ method and techniques in which only a single ${ }^{85} \mathrm{Kr}$ or ${ }^{183} \mathrm{Xe}$ myocardial washout curve is measured after a bolus coronary injection overestimate average LV myocardial flow/unit mass because areas of reduced perfusion are inadequately represented in the single washout curve $(7,26)$.

Radiographically significant coronary disease: regional $L V$ perfusion. In the patients with isolated LAD lesions, the average regional myocardial blood flow distal to the lesions did not differ significantly from that of the remainder of the ventricle. Since the average LAD arteriographic lesion (score, 38) corresponds to a $60-80 \%$ obstruction, this may be additional evidence in man that lesions $<80 \%$ do not reduce resting myocardial blood flow (21). In the patients with significant LAD and right coronary disease, however, the average regional perfusion distal to the lesion was significantly lower than in the remainder of the LV. Inspection of Table II indicates that in five patients with LAD + right disease, the average $\mathrm{LAD}$ score was 25 , corresponding to a $50-60 \%$ stenosis; perfusion distal to the lesion in these patients was not different from the rest of the ventricle.
In 10 others, there was a mean LAD score of 50 , indicating total LAD occlusion; in these patients, the myocardial perfusion distal to the lesion $(41 \mathrm{ml} / 100 \mathrm{~g} \cdot \mathrm{min})$ was significantly lower than in the remainder of the LV (49 $\mathrm{ml} / 100 \mathrm{~g} \cdot \mathrm{min})$. These data suggest therefore, that resting myocardial perfusion is not selectively reduced distal to a coronary stenosis until the lumen diameter has been reduced $90-100 \%$. Bunnell et al., in a preliminary communication (27), reported that the LAD regional perfusion rates measured at rest with the $\mathrm{He}$ washout technique and sampling of the great cardiac vein were normal in the majority of a group of patients with isolated LAD stenoses of less than $90 \%$ but were reduced below controls in those with $90-100 \%$ lesions. Perhaps vasodilitation of coronary arterioles distal to the large vessel lesions maintains resting myocardial capillary blood flow at or near normal basal levels $(22,28)$.

Seven of the patients with total LAD occlusions in this group had previous myocardial infarction and selective reduction of myocardial perfusion in the regions of infarction. This confirms a previous study of 10 patients with anterior transmural infarction and $>90 \%$ stenoses of the LAD whose resting myocardial blood flow/unit mass was reduced in the LAD region (29).

Average perfusion distal to the LAD lesions in the patients with LAD + right coronary disease was significantly lower than the average perfusion in the LAD area in the controls (Fig. 3). An unexplained observation in this group was that regional flow in the Circ. area was also depressed in left coronary studies in patients with significant LAD disease even though the degree of Circ. disease apparent on the arteriograms was insignificant (Table II).

Methodological considerations. One possible explanation for the observation that regional myocardial flow was sometimes reduced in areas where significant disease was not visualized and for the poor correlations between perfusion and arteriographic score is imprecision in the technique of coronary arteriography itself. Radiologists have remarked upon the difficulty in discerning the exact degree of concentric narrowing of a coronary blood vessel from a single-plane cine or cut film (14). Pathologists have observed that the extent and amount of atherosclerotic coronary disease found at autopsy in patients with ischemic heart disease often exceeds that anticipated from antemortem coronary arteriograms $(30,31)$.

Alternatively, the poor correlations may be related to deficiencies of the technique to measure regional myocardial blood flow. A detailed discussion and critique of the method used in the present studies has been presented elsewhere $(8,12)$ along with a discussion of its limitations and advantages. One of the limitations is that the 
studies of regional perfusion at rest (Tables I and II) were performed with the patient in the LAO position only. (The limited radiation detection efficiency of the multiple-crystal camera precluded use of thicker collimators, so that multiple measurements in different projections could not be performed [8].) The LAO projection displays the myocardial region supplied by the LAD artery with little overlap of other myocardial tissue supplied by the same vessel; areas distal to Circ. lesions are often overlapped by tissue supplied by the same artery, however.

Comparative measurements of regional myocardial perfusion with ${ }^{133} \mathrm{Xe}$ and the multiple-crystal scintillation camera and with radioactive microspheres have not yet been performed in experimental animals. Nevertheless, in four published studies $(2,32-34)$ there was a close correspondence over a wide range of values between left coronary flow per $100 \mathrm{~g}$ myocardium measured with a flowmeter and blood flow per $100 \mathrm{~g}$ myocardium measured with radioxenon and calculated by monoexponential analysis of the initial portions of single-tracer washout curves.

It has been shown that ${ }^{133} \mathrm{Xe}$ measurements (single myocardial washout curves) overestimated mean LV flow per unit mass of tissue in the presence of experimental coronary constrictions because low flow regions received inadequate representation in the single washout measurement $(7,26)$. We believe that regions of reduced myocardial perfusion are represented in the measurements of mean LV perfusion using ${ }^{133} \mathrm{Xe}$ and the multiple-crystal camera, however $(8,12)$. Even though a bolus injection of tracer is used, the multiple detectors and the multichannel collimator divide the myocardium into discrete regions. Perfusion rates in the different localities are measured separately and averaged to obtain a mean flow per $100 \mathrm{~g} \cdot \min$ for the $\mathrm{LV}$ in which areas of high and low flow receive proportionate representation. Several other observations support this belief : (a) our finding in this and a previous study (6) that average mean LV perfusion was indeed significantly reduced in a large number of patients with coronary disease and $(b)$ the observation that the average mean $\mathrm{LV}$ flow values obtained with ${ }^{1: 3} \mathrm{Xe}$ in these patients with two- and three-vessel disease are almost identical to those reported by other groups measuring mean LV perfusion in patients with coronary artery disease with $\mathrm{H}_{2}$ and $\mathrm{He}$ washout curves $(7,25)$.

Another significant limitation of the measurement technique used in these studies is its inability in its present form to distinguish epicardial from endocardial blood flow $(8,12)$. Nevertheless, we believe that the measurement obtained in each region represents a weighted average of the blood flow rates across myocardial tissue viewed by an individual crystal. The monoexponential analysis of the initial slope of the ${ }^{133} \mathrm{Xe}$ curve approximates the derivative at time zero of the curve. In the presence of transmural heterogeneity of perfusion in coronary disease, the initial slope analysis of a multiexponential tracer washout curve would yield a rate constant which is the average of the different flow compartments in the tissue which is weighted by the relative total flow to each compartment. To test this hypothesis, biexponential ${ }^{123} \mathrm{Xe}$ washout curves were generated with rate constants such that flow rates in endocardial and epicardial myocardium were equal to those obtained by Becker et al. (35) and Neil et al. (36), and intercepts were proportional to the total flow in the two regions. When these curves were analyzed by initial slope monoexponential analysis, the flow rates obtained differed by less than $5 \%$ from average flow rates calculated by using the microsphere data. They were never directionally opposite, even though the endo-epi flow ratios ranged from 0.67 to 1 (ratios similar to those reported for experimental coronary stenosis at rest and during induced tachycardia) $(35,36)$. Therefore, it appears that in the present measurements alterations in subendocardial perfusion are merged in a weighted average flow measurement. In the patients with insignificant reductions in total or regional myocardial perfusion ("mild" disease, isolated LAD disease) or in those with significant reductions ( $\mathrm{LAD}+$ right, $\mathrm{LAD}+$ Circ., $\mathrm{LAD}+$ Circ. + right) reductions of subendocardial perfusion could have been relatively greater.

Phy'siological interpretations. Although reductions in mean LV myocardial blood flow/unit mass of tissue were found in the patients with radiographically significant two-ressel coronary disease, the data do not provide quantitative information concerning total LV perfusion (milliliters per minute) since LV mass was not estimated. It does not seem probable, however, that the $>20 c_{c}^{c}$ reduction of blood flow/unit mass could be accounted for by an increased volume of scar tissue or by myocardial hypertrophy because 23 of the 70 patients with two- and three-vessel disease had no ECG or historical evidence of infarction. Cardiomegaly was noted by $\mathrm{X}$ ray in only 29 , and LV hypertrophy was apparent in only 11 (Table I). Other groups of investigators have used radiolabeled $\mathrm{Rb}^{+}$and $\mathrm{K}^{+}$and precordial detectors to make estimates of "total myocardial flow" in milliliters per minute in the hearts of control subjects and patients with coronary atherosclerosis. While the data is conflicting, the majority of workers have reported reductions of total myocardial flow in coronary artery disease $(37-40)$. This suggests that the reduced myocardial flow/unit mass in two- and three-vessel disease resulted predominantly from a diminution in coronary blood flow rather than from an increase in the mass of tissue. The average $23 \%$ coefficient of variation of local LV per- 
fusion rates in the patients with involvement of three vessels exceeded that of the controls. This confirms previous reports $(6,19,41)$ that heterogeneity of regional $\mathrm{LV}$ myocardial blood flow rates is increased in patients with significant coronary disease.

None of the patients with reduced resting myocardial blood flow/unit mass of tissue experienced angina or manifested ischemia ECG changes during the studies. Measurements of the arterial-coronary sinus blood oxygen concentration difference made at rest by other workers have usually been normal $(42,43)$. These observations suggest that despite a reduced blood flow, the diseased myocardium of the patients with coronary disease may not be ischemic at rest. In 36 of the 70 patients with significant two- or three-vessel disease LVEDP was increased and in 53 ventricular function was abnormal. It is possible that depressed ventricular performance may lower the oxygen requirements of the heart. Thus, a lower level of perfusion may adequately supply the reduced metabolic needs of the diseased myocardium at rest. This speculation is supported not only by the observations in the coronary patients but also by the reduced resting LV perfusion values found in patients with impaired ventricular function with cardiomyopathy (Fig. 4), primary myocardial disease (24), and mitral stenosis (44) and by experimental studies in animals with induced heart failure $(23,45)$ or controlled reductions of coronary artery flow (46).

Clinical considerations. The method used to measure regional myocardial blood flow with ${ }^{133} \mathrm{Xe}$ and a scintillation camera in these studies is still under development. Some of its limitations and the problems currently under investigation are discussed in detail in other reports $(8$, 12). The focus of the present studies was to obtain resting perfusion data (in the LAO projection) on groups of patients with similar coronary arteriographic lesions and to make inferences only from statistically significant bodies of data. The present studies suggest to us that interpretation of coronary lesions visualized radiographically in individual patients will be maximized when multiple regional myocardial blood flow measurements can be made in several projections in order to view regions distal to coronary lesions optimally with minimal overlap of other tissue supplied by the same artery. They also suggest that physiological significance of coronary lesions in terms of flow will be maximized when the studies of regional myocardial perfusion are performed not only at rest but during an intervention which increases myocardial oxygen consumption.

\section{ACKNOWLEDGMENTS}

The authors wish to gratefully acknowledge assistance on this project of Drs. George Mallis and David Blood, Ms. Katalin Boros for technical assistance, and Ms. Rita Due Mogensen for typing the manuscript.
This work was supported by grants HL 14148 and HL 14236 from the National Institutes of Health of the U. S. Public Health Service.

\section{REFERENCES}

1. Rowe, G. G., J. H. Thomsen, R. R. Stenlund, D. H. McKenna, S. Sialer, and R. J. Corliss. 1969. A study of hemodynamics and coronary blood flow in man with coronary artery disease. Circulation. 39: 139-148.

2. Ross, R. S., K. Ueda, P. R. Lichtlen, and J. R. Rees. 1964. Measurement of myocardial blood flow in animals and man by selective injection of radioactive inert gas into the coronary arteries. Circ. Res. 15: 28-41.

3. Cohen, L. S., W. C. Elliott, M. D. Klein, and R. Gorlin. 1966. Coronary heart disease. Clinical, cinearteriographic and metabolic correlations. Am. J. Cardiol. 17: 153-168.

4. Holmberg, S., S. Paulin, I. Prěrovský, and E. Varnauskas. 1967. Coronary blood flow in man and its relation to the coronary arteriogram. Am. J. Cardiol. 19: 486-491.

5. Horwitz, L. D., G. C. Curry, R. W. Parkey, and F. J. Bonte. 1974. Differentiation of physiologically significant coronary artery lesions by coronary blood flow measurements during isoproteranol infusion. Circulation. 49: 55-62.

6. Cannon, P. J., R. B. Dell, and E. M. Dwyer, Jr. 1972. Regional myocardial perfusion rates in patients with coronary artery disease. J. Clin. Invest. 51: 978-994.

7. Klocke, F. J., I. L. Bunnell, D. G. Greene, S. M. Wittenberg, and J. P. Visco. 1974. Average coronary blood flow per unit weight of left ventricle in patients with and without coronary artery disease. Circulation. 50: 547-559.

8. Cannon, P. J., R. B. Dell, and E. M. Dwyer, Jr. 1972. Measurement of regional myocardial perfusion in man with ${ }^{133}$ xenon and a scintillation camera. J. Clin. Invest. 51 : 964-977.

9. Kety, S. S. 1960. I. Blood-tissue exchange methods. Theory of blood-tissue exchange and its application to measurement of blood flow. Methods Med. Res. 8: 223227.

10. Judkins, M. P. 1967. Selective coronary arteriography. I. A percutaneous transfemoral technic. Radiology. 89: 815-824.

11. Jaffe, C. C., and K. Ellis. 1974. Angiocardiographic quantitation of ventricular volume, shape and mass. Curr. Prob. Radiol. 4 : 1-55.

12. Cannon, P. J., R. R. Sciacca, D. L. Fowler, M. B. Weiss, D. H. Schmidt, and W. J. Casarella. 1975. Regional myocardial blood flow in man: description and critique of the method using ${ }^{133}$ xenon and a scintillation camera. Am. J. Cardiol. 36: 783-792.

13. Conn, H. L., Jr. 1961. Equilibrium distribution of radioxenon in tissue: xenon-hemoglobin association curve. J. Appl. Phy'siol. 16: 1065-1070.

14. Abrams, H. L., and D. F. Adams. 1971. Coronary arteriography. In Angiography. H. L. Abrams, editor. Little, Brown and Company, Boston, 2nd edition. 1: 421-422.

15. Bing, R. J. 1951. The coronary circulation in health and disease as studied by coronary sinus catheterization. Bull. N. Y. Acad. Med. 27 : 407-424.

16. Regan, T. J., G. Timmis, M. Gray, K. Binak, and H. K. Hellems. 1961. Myocardial oxygen consumption 
during exercise in fasting and lipemic subjects. J. Clin. Invest. 40: 624-630.

17. Ganz, W., K. Tamura, H. S. Marcus, R. Donoso, S. Yoshida, and H. J. C. Swan. 1971. Measurement of coronary sinus blood flow by continuous thermodilution in man. Circulation. 44: 181-195.

18. Domenech, R. J., J. I. E. Hoffman, M. I. M. Noble, K. B. Sauders, J. R. Hensen, and S. Subijanto. 1969. Total and regional coronary blood flow measured by radioactive microspheres in conscious and anesthetized dogs. Circ. Res. 25 : 581-596.

19. Sullivan, J. M., W. J. Taylor, W. C. Elliott, and R. Gorlin. 1967. Regional myocardial blood flow. J. Clin. Invest. 46: 1402-1412.

20. Utley, J., E. L. Carlson, J. I. E. Hoffman, H. M. Martinez, and G. D. Buckberg. 1974. Total and regional myocardial blood flow measurements with $25 \mu$, $15 \mu, 9 \mu$ and filtered $1-10 \mu$ diameter microspheres and antipyrine in dogs and sheep. Circ. Res. 34: 391-405.

21. Smith, S. C., Jr., R. Gorlin, M. V. Herman, W. J. Taylor, and J. J. Collins, Jr. 1972. Myocardial blood flow in man: effects of coronary collateral circulation and coronary artery bypass surgery. J. Clin. Ini'est. 51: 2556-2565.

22. Gould, K. L., K. Lipscomb, and G. W. Hamilton. 1974. Physiological basis for assessing critical coronary stenosis. Instantaneous flow response and regional distribution during coronary hyperemia as measures of coronary flow reserve. Am. J. Cardiol. 33: 87-94.

23. Graham, T. P., Jr., J. Ross, Jr., J. W. Covell, E. H. Sonnenblick, and R. L. Clancy. 1967. Myocardial oxygen consumption in acute experimental cardiac depression. Circ. Res. 21: 123-138.

24. Henry, P. D., D. Eckberg, J. H. Gault, and J. Ross, Jr. 1973. Depressed inotropic state and reduced myocardial oxygen consumption in the human heart. Am. J. Cardiol. 31: 300-306.

25. Hodges, M., T. Akiyama, T. L. Biddle, D. L. Roberts, and B. Wynar. 1973. Coronary blood flow in acute myocardial infarction in man. Am. J. Cardiol. 31: 138. (Abstr.)

26. Klocke, F. J., D. R. Rosing, and D. E. Pitman. 1969. Inert gas measurements of coronary blood flow. Am. J. Cardiol. 23: 548-555.

27. Bunnell, I., F. Klocke, D. Greene, D. Arani, R. Tandon, R. Oliveros, and S. Wittenberg. 1974. Effects of isolated left anterior descending coronary artery stenoses on coronary blood flow. J. Clin. In'est. 53: 13a. (Abstr.)

28. McGregor, M., and W. M. Fam. 1966. Regulation of coronary blood flow. Bull. N. Y. Acad. Mcd. 42: 940950.

29. Dwyer, E. M., Jr., R. B. Dell, and P. J. Cannon. 1973. Regional myocardial blood flow in patients with residual anterior and inferior transmural infarction. Circulation. 48: 924-935.

30. Kemp, H. G., H. Evans, W. C. Elliott, and R. Gorlin. 1967. Diagnostic accuracy of selective coronary cinearteriography. Circulation. 36: 526-533.

31. Vlodaver, Z., R. Frech, R. A. Van Tassel, and J. E.
Edwards. 1973. Correlation of the antemortem coronary arteriogram and the post mortem specimen. Circulation. $47: 162-169$.

32. Herd, J. A., M. Hollenberg, G. D. Thorburn, H. H. Kopald, and A. C. Barger. 1962. Myocardial blood flow determined with krypton 85 in unanesthetized dogs. Am. J. Physiol. 203: 122-124.

33. Bassingthwaighte, J. B., T. Strandell, and D. E. Donald. 1968. Estimation of coronary blood flow by washout of diffusible indicators. Circ. Res. 23: 259-278.

34. Shaw, D. J., A. Pitt, and G. C. Friesinger. 1971. Autoradiographic study of the ${ }^{133}$ xenon disappearance method for measurement of myocardial blood flow. Cardiozasc. Res. $6:$ : 268-276.

35. Becker, L. C., N. J. Fortuin, and B. Pitt. 1971. Effect of ischemia and antianginal drugs on distribution of radioactive microspheres in the canine left ventricle. Circ. Res. 28: 263-269.

36. Neill, W. A., J. Oxendine. N. Phelps, and R. P. Anderson. 1975. Subendocardial ischemia provoked by tachycardia in conscious dogs with coronary stenosis. Am. J. Cardiol. 35: 30-36.

37. Donato, L., G. Bartolomei, and R. Giordani. 1964. Evaluation of myocardial blood perfusion in man with radioactive potassium or rubidium and precordial counting. Circulation. 29: 195-203.

38. Cowan, C., P. V. M. Duran, G. Corsini, N. Goldschlager, and R. J. Bing. 196\%. The effects of nitroglycerin on myocardial blood flow in man. Measured by coincidence counting and bolus injections of ${ }^{84}$ rubidium. Am. J. Cardiol. 24: 154-160.

39. Mymin, D., and G. P. Sharma. 1974. Total and effective coronary blood flow in coronary and noncoronary heart disease. J. Clin. Ini'cst. 53: 363-373.

40. Knoebel, S. B., P. L. McHenry, J. F. Phillips, and F. J. Pauletto. 1972. Coronary collateral circulation and myocardial blood flow reserve. Circulation. 46: 84-94.

41. Klocke, F. J., and S. M. Wittenberg. 1969. Heterogeneity of coronary blood flow in human coronary disease and experimental myocardial infarction. Am. $J$. Cardiol. 24 : 782-790.

42. Helfant, R. H., J. S. Forrester, J. R. Hampton, J. I. Haft, H. G. Kemp, and R. Gorlin. 1970. Coronary heart disease. Differential hemodynamic, metabolic, and electrocardiographic effects in subjects with and without angina pectoris during atrial pacing. Circulation. 42: 601-610.

43. Messer, J. V., and W. A. Neill. 1962. The oxygen supply of the human heart. Am. J. Cardiol. 9: 384-394.

44. Rowe, G. G., G. M. Maxwell, C. A. Castillo, J. H. Huston, and C. W. Crumpton. 1960. Hemodynamics of mitral stenosis with special reference to coronary blood flow and myocardial oxygen consumption. Circulation. 22: 559-562.

45. Braunwald, E. 1971. Control of myocardial oxygen consumption. Physiologic and clinical considerations. Am. J. Cardiol. $27: 416-432$.

46. Lekven, J., O. D. Mjøs, and J. K. Kjekshus. 1973. Compensatory mechanisms during graded myocardial ischemia. Am. J. Cardiol. 31: 467-473. 